TI 2013-202/VI

Tinbergen Institute Discussion Paper

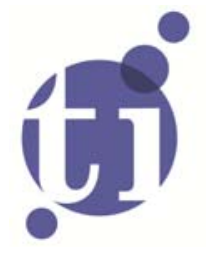

\title{
Non-Marginal Cost-Benefit Analysis and the Tyranny of Discounting
}

Koen Vermeylen 
Tinbergen Institute is the graduate school and research institute in economics of Erasmus University Rotterdam, the University of Amsterdam and VU University Amsterdam.

More TI discussion papers can be downloaded at http://www.tinbergen.nl

Tinbergen Institute has two locations:

Tinbergen Institute Amsterdam

Gustav Mahlerplein 117

1082 MS Amsterdam

The Netherlands

Tel.: +31(0)205251600

Tinbergen Institute Rotterdam

Burg. Oudlaan 50

3062 PA Rotterdam

The Netherlands

Tel.: +31(0)10 4088900

Fax: $+31(0) 104089031$

Duisenberg school of finance is a collaboration of the Dutch financial sector and universities, with the ambition to support innovative research and offer top quality academic education in core areas of finance.

DSF research papers can be downloaded at: http://www.dsf.nl/

Duisenberg school of finance

Gustav Mahlerplein 117

1082 MS Amsterdam

The Netherlands

Tel.: +31(0)20 5258579 


\title{
Non-Marginal Cost-Benefit Analysis and the Tyranny of Discounting
}

\author{
Koen Vermeylen* \\ University of Amsterdam
}

May 31, 2013

*I thank seminar participants at the 19th Annual Conference of the European Association of Environmental and Resource Economists (EAERE). Please contact the author for all correspondence: Department of Economics, University of Amsterdam, Roetersstraat 11, 1018 WB Amsterdam, The Netherlands; tel.: +(31)-(20)-5254192; fax: +(31)-(20)-5254254; e-mail: K.Vermeylen@uva.nl. 


\begin{abstract}
This paper uses the Kaldor-Hicks compensation principle to compute the present value (PV) of a non-marginal future event. Three theoretical results stand out: first, decreasing returns to capital create a wedge between the PV of future generations' willingness to pay (WTP) and the PV of their willingness to accept compensation (WTA); second, the discount rates implicit in the computation of the PVs are endogenous, and rising (declining) over time for the future generations' WTP (WTA); and third, decreasing returns to capital may make it impossible to compensate future generations according to their WTA, effectively defeating the tyranny of discounting. A back-of-the-envelope calibration suggests that this last result is realistic in the case of climate change. A cost-benefit analysis based on the Kaldor-Hicks compensation principle may therefore be impossible if future generations are entitled to a world without climate change; and an environmental trust fund - no matter how large it is may be insufficient to adequately compensate future generations.
\end{abstract}

Keywords: climate change, cost-benefit analysis, discounting, WTP, WTA

JEL Codes: D61, E13, H43, Q51, Q54 


\section{Introduction}

At the heart of cost-benefit analysis (CBA) is the Kaldor-Hicks compensation principle (Hicks, 1939, 1943; and Kaldor, 1939), which states that a project should be implemented if and only if it may lead to a Pareto-improvement: those who gain from the project should be able to compensate the losers and have some net gains left over. The Kaldor-Hicks compensation principle is often invoked as the theoretical underpinning for discounting future (monetary) costs and benefits with the rate of return on capital: ${ }^{1}$ if costs and benefits take place at different times, the gainers from a project can compensate the losers by transferring resources over time through capital investment or desinvestment; the gross rate of return is then the price of current resources relative to resources in the future.

But discounting with market rates of return yields very low present values for costs and benefits that take place in the distant future, even when these costs and benefits are monumental relative to the size of the future economy. This phenomenon is called the tyranny of discounting, ${ }^{2}$ and has been brought to the fore of the research agenda by the economics of climate change. To paraphrase Weitzman (1998): when applying standard discounting techniques to compute the present value of the impact of climate change, many economists have "an uneasy intuitive feeling that something is wrong, somewhere". This has lead to a burgeoning literature that calls for declining discount rates (DDRs) in climate change CBAs. ${ }^{3}$

Monumental costs and benefits, however, are likely to affect the price at which resources are transferred over time when the gainers compensate the losers according to the Kaldor-Hicks compensation principle. Monumental events should therefore not be discounted with exogenously determined interest rates (whether or not they are declining), but with endogenous discount rates. The objective of this paper is to illustrate this in an economy with climate change, and to show how this may defeat the tyranny of discounting.

\footnotetext{
${ }^{1}$ Another motivation for using the rate of return on capital as the discount rate follows from maximizing the utility of a representative agent in a Ramsey model, which is worked out in the descriptive approach to discounting (Arrow et al., 1996). However, the descriptive approach to discounting assumes that consumption is allocated across time in a socially optimal way, which is not required for the Kaldor-Hicks compensation principle. Goulder and Williams (2012) explain the difference between the descriptive approach to discounting and the Kaldor-Hicks compensation principle in more detail.

${ }^{2}$ See Portney and Weyant (1999) and Pearce et al. (2003).

${ }^{3}$ For theoretical motivations for DDRs, see Gollier and Weitzman (2010); Gollier and Zeckhauser (2005); and Farmer and Geanakoplos (2009). For empirical implementations, see Newell and Pizer (2003); Groom et al. (2007); Gollier (2008); Gollier et al. (2008); and Hepburn et al. (2009).
} 
The line of reasoning and the outline of the paper are as follows.

In section 2 , I present an economy where climate change causes abatement costs at the expense of future consumption levels, which could be avoided by implementing a mitigation project today. I will assume decreasing returns to capital. This assumption is crucial: constant returns to capital would not support the conclusions of the paper.

In section 3, I apply the Kaldor-Hicks compensation principle to investigate whether the mitigation project should be implemented. It turns out that this depends on the standing of current and future generations. If the project is implemented and if future generations have to compensate the current generation for her expenses, the Kaldor-Hicks compensation principle calls for less capital accumulation over time, which increases the rate of return and the appropriate discount rate. But if the project is not implemented and if the current generation has to compensate future generations for failing to implement the project, the Kaldor-Hicks compensation principle calls for more capital accumulation, which drives down the rate of return and the appropriate discount rate; if the rate of return becomes too low and reaches its golden rule level, it may even be impossible to set aside sufficient extra capital to adequately compensate future generations.

I therefore find that decreasing returns to capital drive a wedge between the present value of the future generations' willingness to pay (WTP) and the present value of their willingness to accept compensation (WTA), and that the present value of their WTA may not exist.

A back-of-the-envelope computation in section 4 suggests that this last result may be realistic: if future generations are entitled to a world without climate change, it may be impossible for the current generation to set aside sufficient capital to adequately compensate future generations if climate change takes place nevertheless - which implies that the consumption losses which future generations will suffer as a result of climate change cannot be discounted in a way which is consistent with the Kaldor-Hicks compensation principle, depriving the tyranny of discounting of its power. Discounting the impact of climate change is then only possible if one takes the stand that future generations are not entitled to a world without climate change.

Section 5 concludes.

\section{The set-up}

Consider an economy where aggregate output $Y$ is a function $F$ of reproducible capital $K$ and a vector of other inputs $X$ (such as effective labor input and 
effective natural capital):

$$
Y_{t}=F\left(K_{t}, X_{t}\right)
$$

The production function $F$ has constant returns to scale and decreasing returns to each of its production factors. The subscript $t$ denotes the time period (the current period being 0). For expositional purposes, I assume that each period corresponds with a different generation (even though this is not necessary for the analysis).

The inputs contained by the vector $X$ all grow at rate $g$. The law of motion of reproducible capital depends on investment $I$ and the depreciation rate $\delta$ (with $0 \leq \delta \leq 1$ ):

$$
K_{t+1}=K_{t}(1-\delta)+I_{t}
$$

Factors of production are paid their marginal products, such that

$$
\frac{\partial F\left(K_{t}, X_{t}\right)}{\partial K_{t}}=r_{t}+\delta
$$

... where $r$ denotes the interest rate.

All production is consumed $(C)$ or invested $(I)$ :

$$
Y_{t}=C_{t}+I_{t}
$$

I assume that the economy follows a balanced growth path, denoted by a superscript ${ }^{*}$, such that aggregate output, reproducible capital and consumption grow at rate $g$, while the interest rate remains constant over time:

$$
\begin{aligned}
\frac{Y_{t+1}^{*}}{Y_{t}^{*}}=\frac{K_{t+1}^{*}}{K_{t}^{*}}=\frac{C_{t+1}^{*}}{C_{t}^{*}} & =1+g, & & \forall t \geq 0 \\
r_{t}^{*} & =r^{*}, & & \forall t \geq 0
\end{aligned}
$$

I also assume that the economy is dynamically efficient ${ }^{4}$ and that the steady state growth rate $g$ is positive:

$$
r^{*}>g>0
$$

\footnotetext{
${ }^{4}$ If the economy is not dynamically efficient, all generations can be made better off by lowering the saving rate, and the economy is not Pareto-optimal. But an economy which is per construction not Pareto-optimal, does not provide a robust basis for a decision theory based on potential Pareto-improvements. Dynamic efficiency is therefore essential for the Kaldor-Hicks compensation principle. I will come back to this point in section 4 .
} 
Note that this set-up boils down to the steady state of a Ramsey model. However, I deliberately did not derive it from the Ramsey model in order to avoid any specification of a utility or social welfare function, as this is not required by the Kaldor-Hicks compensation principle. ${ }^{5}$

Assume now that it becomes clear in period 0 that climate change will cause abatement costs from some period $T>0$ onwards, which will, ceteris paribus, decrease consumption with $\sigma Y_{t}^{*}$ in every period $t \geq T$ (with $0<\sigma<C_{t}^{*} / Y_{t}^{*}$ ); and assume that these consumption losses can be avoided by spending $\Omega$ on a project in period 0 . In the next section, I analyze whether this project should be implemented according to the Kaldor-Hicks compensation principle.

\section{The Kaldor-Hicks compensation principle}

The Kaldor-Hicks compensation principle requires specifying the standing of different generations. The first possibility is that the current generation has no obligation (legally or morally) to protect future generations against the impact of climate change. In this case, future generations would gain from the project, while the current generation, who has to bear its cost, would lose. The question is then how much the future generations' WTP is for the project, how much this would be worth in present value terms for the current generation, and whether this would be more or less than the cost of the project. The second possibility is that the current generation does have an obligation to protect future generations against the impact of climate change. In that case, the current generation would gain from the project, as it would free her from her obligation to set aside sufficient extra capital to compensate future generations for the impact of climate change. The question is then how much the future generations' WTA is if the project is not implemented, how much extra capital the current generation would have to set aside to accomodate this, and whether this is more or less than the cost of the project.

I first derive expressions for the present value of the future generations' WTP and the present value of their WTA. I then present some propositions.

\subsection{The present values of the future generations' WTP and WTA}

First note that if the felicity of the generation in period $t$ only depends on $C_{t}$, she would be willing to pay up to $\sigma Y_{t}^{*}$ of consumption goods to avoid climate

5 ... which differentiates my approach from Dietz and Hepburn's (2010) and Gollier's (2011) approach, who analyze non-marginal CBAs for a well-specified social welfare function. 
change in period $t$; and she would need a minimum of $\sigma Y_{t}^{*}$ as compensation for it. So both her WTP and WTA, measured in consumption goods of period $t$ and related to the damage caused in period $t$, are equal to $\sigma Y_{t}^{*}$.

Consider now the case where the current generation has no obligations towards future generations. How could the future generations' WTP then lead to a compensation for the current generation if the current generation implements the project?

If future generations pay for the project by giving up $\sigma Y_{t}^{*}$ in consumption goods in every period $t \geq T$, their consumption becomes $C_{t}^{*}-\sigma Y_{t}^{*}$ for $t \geq T$, which requires a lower capital stock in period $T$. The level of this capital stock, $K_{T}^{P}$, can be computed by combining the production function (1), the capital stock's law of motion (2) and the goods market's equilibrium condition (4), taking into account that the steady state growth rate of $K, X, C$ and $Y$ is equal to $g$ :

$$
F\left(K_{T}^{P}, X_{T}\right)=C_{T}^{*}-\sigma Y_{T}^{*}+(\delta+g) K_{T}^{P}
$$

Future generations are therefore willing to settle for a capital stock $K_{T}^{P}$, with $K_{T}^{P}<K_{T}^{*}$, if the current generation goes ahead with the project. From equations (1), (2) and (4) follows then (implicitly) the corresponding capital stock in period $T-1$, assuming that consumption in period $T-1$ remains at its steady state level $C_{T-1}^{*}$ :

$$
F\left(K_{T-1}^{P}, X_{T-1}\right)=C_{T-1}^{*}+K_{T}^{P}-(1-\delta) K_{T-1}^{P},
$$

Iterating backwards until period 1 yields $K_{1}^{P}$, such that the corresponding investment level in period 0 is given by

$$
I_{0}^{P}=K_{1}^{P}-(1-\delta) K_{0}^{*}
$$

Note that as $K_{T}^{P}<K_{T}^{*}$, the required investment in period $0, I_{0}^{P}$, is below its steady state value $I_{0}^{*}$. The difference between $I_{0}^{*}$ and $I_{0}^{P}$ is the present value of the future generations' WTP, and can be used to compensate the current generation if she goes ahead with the project:

$$
P V_{0}^{P}=I_{0}^{*}-I_{0}^{P}
$$

If $P V_{0}^{P}>\Omega$, the present value of the future generations' WTP is larger than what the current generation has to pay for the project; implementing the project creates then the possibility of a Pareto-improvement, and the project passes the cost-benefit test. If $P V_{0}^{P} \leq \Omega$, a Pareto-improvement cannot be established, and the project should be discarded. 
Consider now the case where the current generation does have the obligation to protect future generations against the impact of climate change. According to their WTA, future generations would be willing to accept $\sigma Y_{t}^{*}$ in consumption goods in every period $t \geq T$ as compensation if the project is not implemented. How costly such a compensation scheme would be for the current generation can be computed in a very similar way as how we computed the present value of the future generations' WTP.

To make sure that future generations have $\sigma Y_{t}^{*}$ extra consumption goods in every period $t \geq T$, they should start off in period $T$ with a higher capital stock $K_{T}^{A}$, which satisfies

$$
F\left(K_{T}^{A}, X_{T}\right)=C_{T}^{*}+\sigma Y_{T}^{*}+(\delta+g) K_{T}^{A}
$$

The corresponding capital stock in period $T-1$, assuming that consumption in period $T-1$ remains at its steady state level $C_{T-1}^{*}$, follows then from

$$
F\left(K_{T-1}^{A}, X_{T-1}\right)=C_{T-1}^{*}+K_{T}^{A}-(1-\delta) K_{T-1}^{A}
$$

Iterating backwards until period 1 yields $K_{1}^{A}$, such that the corresponding investment level in period 0 is given by

$$
I_{0}^{A}=K_{1}^{A}-(1-\delta) K_{0}^{*}
$$

As $K_{T}^{A}>K_{T}^{*}$, it follows that $I_{0}^{A}>I_{0}^{*}$. The difference between $I_{0}^{A}$ and $I_{0}^{*}$ is then the present value of the future generations' WTA:

$$
P V_{0}^{A}=I_{0}^{A}-I_{0}^{*}
$$

If $P V_{0}^{A}>\Omega$, it is more expensive for the current generation to set aside extra capital to compensate future generations for climate change than to avoid climate change by implementing the project; implementing the project creates then a Pareto-improvement, and the project passes the cost-benefit test. If $P V_{0}^{A} \leq \Omega$, there is no scope for a Pareto-improvement, and the project should be discarded.

\subsection{Propositions}

Let us now compare the expressions for $P V_{0}^{P}$ and $P V_{0}^{A}$.

First note that if $\sigma$ is arbitrarily small, $P V_{0}^{P}$ and $P V_{0}^{A}$ are equal to each other and can be computed with standard discounting techniques:

Proposition 1 If $\sigma$ is arbitrarily small, consumption losses of future generations are discounted with the interest rate $r^{*}$, independent of the standing of future generations, and $P V_{0}^{P}=P V_{0}^{A}$. 
Proof: Let us first compute $P V_{0}^{P}$. Subtract from equation (6) the corresponding expression for the steady state without climate change, take into account that $\sigma$ is arbitrarily small, denote $d K_{T}^{P}=K_{T}^{P}-K_{T}^{*}$, and recall that the marginal product of capital around the steady state is given by equation (3); reshuffling gives then $d K_{T}^{P}=-\sigma Y_{T}^{*} /\left(r^{*}-g\right)$. In a similar way, an arbitrarily small value of $\sigma$ allows us to transform equation (7) into $d K_{T-1}^{P}=d K_{T}^{P} /\left(1+r^{*}\right)$. Iterating backwards until period 1 yields then $d K_{1}^{P}$, which is equal to $-P V_{0}^{P}$ according to equations (8) and (9). This yields $P V_{0}^{P}=\sigma Y_{T}^{*} /\left[\left(r^{*}-g\right)\left(1+r^{*}\right)^{T-1}\right]$. $P V_{0}^{A}$ can be computed in a similar way, leading to the same expression. Note that $P V_{0}^{P}$ and $P V_{0}^{A}$ are simply the sum of the consumption losses of future generations discounted with the interest rate $r^{*}: P V_{0}^{P}=P V_{0}^{A}=\sum_{s=T}^{\infty} \sigma Y_{s}^{*} /\left(1+r^{*}\right)^{s}$. Q.E.D.

But what happens when $\sigma$ is not arbitrarily small?

Consider equations (6) and (10), which (implicitly) define $K_{T}^{P}$ and $K_{T}^{A}$, respectively. As long as $F\left(0, X_{T}\right)=0$, the Intermediate Value Theorem guarantees a solution for $K_{T}^{P}$ (which must lie between 0 and $K_{T}^{*}$ ). But this is not the case for $K_{T}^{A}$ (which, if it exists, must be above $K_{T}^{*}$ ): if the capital stock grows at its steady state growth rate and its level is large enough, the marginal product of capital may be so low that a small addition in the capital stock generates output that is only sufficient for the extra investment which is needed to make sure that the capital stock continues to grow at its steady state growth rate (in which case the economy is in its golden rule); if this level of the capital stock is not sufficient to cover the abatement costs without cutting consumption levels, an even higher capital stock will not be sufficient for this either, and $K_{T}^{A}$ does not exist. But if $K_{T}^{A}$ does not exist, future generations cannot be adequately compensated for the damage which climate change will bring about, and the PV of their WTA cannot be computed. ${ }^{6}$ This leads to the following proposition:

Proposition 2 If the steady state consumption level without climate change plus the abatement costs is larger than the output level net of investment in the golden rule, it is impossible to amass sufficient capital to satisfy the future generations' WTA, and its present value, $P V_{0}^{A}$, does not exist.

Proof: Define $G\left(K_{T}\right)=F\left(K_{T}, X_{T}\right)-(\delta+g) K_{T}$. Due to decreasing returns to capital, the function $G\left(K_{T}\right)$ is bounded from above, reaching a maximum if $\partial F\left(K_{T}, X_{T}\right) / \partial K_{T}=\delta+g$. Denote the value of $K_{T}$ for which $G\left(K_{T}\right)$ reaches a maximum by $K_{T}^{G R}$ (where the superscript refers to the golden rule). From equation (10) follows then that $K_{T}^{A}$ does not exist if $C_{T}^{*}+\sigma Y_{T}^{*}>G\left(K_{T}^{G R}\right)$; and if $K_{T}^{A}$ does not exist, $P V_{0}^{A}$ does not exist either. Q.E.D.

\footnotetext{
${ }^{6}$ Note that the PV of the future generations' WTA is then not even infinity: even an infinitely large trust fund in period 0 would not be sufficient to accommodate the future generations' WTA.
} 
Suppose now that $K_{T}^{A}$ exists; and recall that the future generations' WTP is equal to their WTA in terms of future consumption goods. Decreasing returns to capital imply then that the extra amount of capital which future generations desire as a compensation for climate change is larger than the amount of capital which they are willing to give up to avoid it; which implies, iterating backwards towards today, that the extra investment which is needed today to accommodate the future generations' WTA is larger than the investment which the current generation can give up and spend on a mitigation project to avoid climate change according to the future generations' WTP. This leads to the third proposition:

Proposition 3 If $P V_{0}^{A}$ exists, then $P V_{0}^{A}>P V_{0}^{P}$.

Proof: $K_{T}^{P}$ and $K_{T}^{*}$ belong to the interval $\left[0, K_{T}^{G R}\right)$; and as $K_{T}^{A}$ exists, $K_{T}^{A}$ belongs to $\left[0, K_{T}^{G R}\right]$; furthermore, we know that $K_{T}^{P}<K_{T}^{*}<K_{T}^{A}$. Now note that equations (6) and (10) imply that $G\left(K_{T}^{A}\right)-G\left(K_{T}^{*}\right)=G\left(K_{T}^{*}\right)-G\left(K_{T}^{P}\right)>0$. As the function $G\left(K_{T}\right)$ is increasing and concave on $\left[0, K_{T}^{G R}\right]$ and strictly increasing and concave on $\left[0, K_{T}^{G R}\right)$, it then follows that $K_{T}^{A}-K_{T}^{*}>K_{T}^{*}-K_{T}^{P}$. Now define $H\left(K_{t}\right)=F\left(K_{t}, X_{t}\right)+(1-\delta) K_{t}$. As $K_{T}^{A}-K_{T}^{*}>K_{T}^{*}-K_{T}^{P}$, equations (7) and (11) imply that $H\left(K_{T-1}^{A}\right)-H\left(K_{T-1}^{*}\right)>H\left(K_{T-1}^{*}\right)-H\left(K_{T-1}^{P}\right)>0$. As the function $H\left(K_{t}\right)$ is strictly increasing and concave, it follows that $K_{T-1}^{A}-K_{T-1}^{*}>$ $K_{T-1}^{*}-K_{T-1}^{P}$. Iterating backwards until period 1 yields $K_{1}^{A}-K_{1}^{*}>K_{1}^{*}-K_{1}^{P}$. From equations (8), (9), (12) and (13) follows then that $P V_{0}^{A}>P V_{0}^{P}$. Q.E.D.

It is clear that if the non-marginal nature of climate change is taken into account, there are no fast and easy rules (such as standard discounting) to compute $P V_{0}^{P}$ and $P V_{0}^{A}$. But once we know $P V_{0}^{P}$ and $P V_{0}^{A}$, we can derive the schedule of discount rates that is implicit in their computations.

Consider first the computation of $P V_{0}^{P}$, which is the amount of investment which the current generation can forgo on behalf of future generations according to their WTP. To compute $P V_{0}^{P}$, we should take into account that if future generations are willing to settle for a lower capital stock in period $T$, the rate of return on capital will increase as the capital stock reaches this lower level - which will drive up the forgone returns on capital in the periods preceding period $T$. So the amount of investment which the current generation can forgo on behalf of future generations according to their WTP will be less than with standard discounting, where the rate of return on capital is not affected by the forgone investment. Or in other words: the computation of $P V_{0}^{P}$ implies a schedule of rising discount rates over time.

The opposite happens in the computation of $P V_{0}^{A}$, which is the extra investment which the current generation should undertake today such that the extra accumulated capital meets the future generations' WTA. To compute $P V_{0}^{A}$, we should take into account that the extra accumulated capital will 
drive down its rate of return - which will also drive down the accumulated returns. So the extra investment which the current generation should undertake to adequately compensate the future generations is larger than with standard discounting, where the rate of return on capital is not affected by the extra investment. Or in other words: the computation of $P V_{0}^{A}$ implies a schedule of declining discount rates over time.

This is summarized in the last proposition:

Proposition 4 The appropriate discount rates to compute $P V_{0}^{P}$ and $P V_{0}^{A}$ are endogenous, and are rising over time for $P V_{0}^{P}$ and declining over time for $P V_{0}^{A}$ until period $T$.

Proof: Let us first prove the statement about the appropriate discount rates to compute $P V_{0}^{P}$. The discount rate for period $t>0$ is then the rate of return on forgone capital in period $t$, which is equal to the forgone output divided by the forgone capital stock, minus the depreciation rate: $\rho_{t}^{P}=\left(F\left(K_{t}^{*}, X_{t}\right)-F\left(K_{t}^{P}, X_{t}\right)\right) /\left(K_{t}^{*}-K_{t}^{P}\right)-\delta$. First note that $\rho_{t}^{P}$ is a function of $K_{t}^{P}$, which depends on $\sigma$; the implicit discount rates are therefore endogenous. Second, subtract equation (7) from the corresponding expression for the steady state without climate change, simplify by using the definition of $\rho_{T-1}^{P}$, and do the same for the corresponding equations for periods $t<T-1$; this yields $K_{t+1}^{*}-K_{t+1}^{P}=\left(1+\rho_{t}^{P}\right)\left(K_{t}^{*}-K_{t}^{P}\right)$, for $t \leq T-1$; dividing both sides by $Y_{t+1}^{*}$, denoting $K / Y^{*}$ by $x$, and recalling that $Y^{*}$ grows at rate $g$ yields then $x_{t+1}^{*}-x_{t+1}^{P}=\left(x_{t}^{*}-x_{t}^{P}\right)\left(1+\rho_{t}^{P}\right) /(1+g)$, for $t \leq T-1$; now note that $\rho_{t}^{P}>g$ as $K_{t}^{P}<K_{t}^{*}<K_{t}^{G R}$; this implies that $x_{t+1}^{*}-x_{t+1}^{P}>x_{t}^{*}-x_{t}^{P}$ for $t \leq T-1$; finally, note that $\partial \rho_{t}^{P} / \partial\left(x_{t}^{*}-x_{t}^{P}\right)>0$; as $x_{t}^{*}-x_{t}^{P}$ increases over time until period $T$ and $\partial \rho_{t}^{P} / \partial\left(x_{t}^{*}-x_{t}^{P}\right)>0$, we then find that $\rho_{t}^{P}$ increases over time until period $T$ as well. The proof of the statement about the appropriate discount rates to compute $P V_{0}^{A}$ is analogous. Q.E.D.

\section{A numerical example}

I now illustrate these propositions with a numerical example. Let us assume a Cobb-Douglas production function,

$$
Y_{t}=K_{t}^{\alpha} \chi_{t}^{1-\alpha}
$$

where $\chi_{t}$ depends on the other inputs $X_{i}$.

According to proposition 2, $P V_{0}^{A}$ can only be computed if $C_{t}^{*}+\sigma Y_{t}^{*} \leq C_{t}^{G R}$, where $C_{t}^{G R}$ is the consumption level in the golden rule without climate change. Let us define the steady state saving rate as $s=1-C_{t}^{*} / Y_{t}^{*}$. The maximum value of $\sigma$ for which $P V_{0}^{A}$ can be computed is then given by

$$
\sigma_{\max }=(1-\alpha)\left(\frac{\alpha}{s}\right)^{\frac{\alpha}{1-\alpha}}-(1-s)
$$

... assuming that $\alpha \geq s$ such that the economy is dynamically efficient. 
Proof: From equations (2), (4), (14), the definition of the saving rate $s$ and the steady state growth rate $g$ follows that $I_{t}^{*}=s K_{t}^{* \alpha} \chi_{t}^{* 1-\alpha}=(\delta+g) K_{t}^{*}$, which yields a closedform solution for $K_{t}^{*}$; substituting in (14) gives $Y_{t}^{*}=(s /(\delta+g))^{\alpha /(1-\alpha)} \chi_{t}$. In the golden rule, $\partial F\left(K_{t}, X_{t}\right) / \partial K_{t}=\delta+g$; from the Cobb-Douglas specification follows then that $\alpha Y_{t}^{G R}=(\delta+g) K_{t}^{G R}$; as $I_{t}^{G R}=(\delta+g) K_{t}^{G R}$, we find that $I_{t}^{G R}=\alpha Y_{t}^{G R}$, which implies that the saving rate in the golden rule is equal to $\alpha$; substituting in the expression which we found above for $Y_{t}^{*}$ gives then $Y_{t}^{G R}=(\alpha /(\delta+g))^{\alpha /(1-1 \alpha)} \chi_{t}$. Now substitute $C_{t}^{*}=(1-s) Y_{t}^{*}$, $C_{t}^{G R}=(1-\alpha) Y_{t}^{G R}$ and the expressions for $Y_{t}^{*}$ and $Y_{t}^{G R}$ found above in the inequality in the proof of proposition $2, C_{t}^{*}+\sigma Y_{t}^{*} \leq C_{t}^{G R}$; this yields expression (15). Note also that if $\alpha<s, K_{t}^{G R}<K_{t}^{*}$ such that the economy is not dynamically efficient. Q.E.D.

According to equation (15), the Cobb-Douglas specification implies that $\sigma_{\max }$ only depends on $\alpha$ and $s$. So let us try to select reasonable values for these two parameters.

Values for $s$ can be found from the Penn World Table (Heston et al., 2011): table 1 presents for a large group of countries the average investment share in total income between 1980 and 2000.

Finding reasonable values for $\alpha$ is more problematic, however. A popular rule-of-thumb is to set $\alpha$ equal to $1 / 3$. This is based on the fact that if the economy has perfectly competitive markets for its production factors, $\alpha$ is equal to the share of capital income in GDP; and as labor income appears to be roughly $2 / 3$ of GDP in most industrialized countries according to their national accounts, $\alpha$ must be about $1 / 3$ if capital and labor are the only factors of production.

But there are at least three problems with this rule-of-thumb. First, it does not take into account that part of GDP is not used to compensate the production factors, but flows to the government as indirect taxes. Second, labor income in the national accounts typically does not include labor income of the self-employed. And third, the production factor $K$ in the Kaldor-Hicks analysis refers to capital that can be accumulated (and therefore reproduced) over time; so it does not include land and natural resources, for instance. In order to find an appropriate value for $\alpha$, we therefore have to subtract from the share of total capital income in GDP the share that goes to non-reproducible capital.

Caselli and Feyrer (2007) take care of these problems by combining data from the national accounts on indirect taxes, estimates from Gollin (2002) and Bernanke and Gurkaynak (2001) of the share of total labor income (including labor income of the self-employed), and data from the World Bank on the share of reproducible capital income in total capital income. The correction for the fact that only part of total capital income is actually a compensation for reproducible capital may well suffer from substantial measurement errors, however. Table 1 therefore presents Caselli and Feyrer's estimates of $\alpha$ both 
before and after subtracting an estimate of the share of non-reproducible capital income. The first estimates of $\alpha$ (neglecting non-reproducible capital) can then be interpreted as upper bounds of the true value of $\alpha$; the second estimates of $\alpha$ (taking account of non-reproducible capital) are Caselli and Feyrer's best estimates. Combining with the corresponding values for $s$ yields then the estimates of $\sigma_{\max }$, which are given in the columns next to those for the values of $\alpha$.

Table 1 shows that for Caselli and Feyrer's best estimates of $\alpha$, most countries are dynamically inefficient. This implies that intertemporal CBAs based on the Kaldor-Hicks compensation principle are pointless, even for arbitrarily small values of $\sigma$. Clearly, this a very strong result. ${ }^{7}$ But as the estimates of the share of non-reproducible capital income are likely to be prone to substantial measurement errors, it is a result that begs for a more careful investigation - which, however, is beyond the scope of this paper.

Let us therefore turn to the upper bounds of $\alpha$, which were computed by neglecting non-reproducible capital. The corresponding values for $\sigma_{\max }$ can be interpreted as upper bounds for their true values. Most economies then appear to be dynamically efficient, with positive values for $\sigma_{\max }$. For all industrialized countries, however, the value for $\sigma_{\max }$ is well below $10 \%$; except for Canada, The Netherlands, Norway, New Zealand and South Africa, it is even below $5 \%$; for the U.S., $\sigma_{\max }$ is $1.7 \%$; and for Japan, $\sigma_{\max }$ is $0.1 \%$. For most if not all industrialized countries, the upper bound of $\sigma_{\max }$ is therefore below the projected costs of climate change. ${ }^{8}$ This suggests that for plausible values of the saving rate and optimistic (upper bound) estimates of $\alpha$, future generations cannot be compensated adequately with extra capital for the impact of climate change, given climate change scenarios that are generally not considered to be unrealistic.

Table 1 therefore suggests that a climate change CBA based on the KaldorHicks compensation principle is not possible if future generations are entitled

\footnotetext{
${ }^{7}$... and not only for intertemporal CBAs: a large part of the modern macroeconomic literature is based on variations of the Ramsey model, and therefore implicitly assumes that the economy is dynamically efficient; so if it turns out that most countries are indeed dynamically inefficient, the most important workhorse model in the modern macroeconomic literature appears to be fundamentally inconsistent with the data.

${ }^{8}$ The Stern Review (Stern, 2007) estimates the total cost of business-as-usual climate change to equate to an average reduction in global per capita consumption of $5 \%$ (now and forever), at a minimum; if non-market impacts and more pessimistic projections of how the climate system responds to greenhouse gas emissions are taken into account, the loss in per capita consumption may be as high as $14 \%$; taking account of the fact that a disproportionate burden of climate change impacts fall on poor regions of the world leads to an estimate of around $20 \%$.
} 
to a world without climate change.

Let us now use the case of the U.S. to illustrate the propositions of the previous section in more detail. According to table 1, the U.S. saving rate is $19 \%$ and the upper bound value for $\alpha$ is $26 \%$. In addition, let us assume that the annual depreciation rate $\delta$ is $8 \%$ and the annual growth rate $g$ is $2 \%$ (which are standard values to calibrate the backbone of a growth model); and let us consider a non-marginal event that hits the U.S. economy 100 years from now, such that $T=100$.

Figure 1 illustrates then propositions 1, 2 and 3, and gives for a range of values of $\sigma$ the corresponding values of $P V_{0}^{P}$ and $P V_{0}^{A}$. First note that for $\sigma$ above $1.7 \%, P V_{0}^{A}$ does not exist - consistent with proposition 2 and Table 1. For lower values of $\sigma, P V_{0}^{A}$ is indeed higher than $P V_{0}^{P}$, which confirms proposition 3. Note also that standard discounting, which disregards the nonmarginal nature of the event, provides a good approximation of $P V_{0}^{P}$ and $P V_{0}^{A}$ for small values of $\sigma$ (in accordance with proposition 1), but quickly causes large mistakes as $\sigma$ increases.

Figure 2 illustrates proposition 4 , and gives the schedule of discount rates implicit in the computation of $P V_{0}^{P}$ and $P V_{0}^{A}$ : discount rates rise over time for $P V_{0}^{P}$, and decline over time for $P V_{0}^{A}$; and the larger $\sigma$, the more pronounced they rise or decline. Note also that for $\sigma=\sigma_{\max }$, the discount rates to compute $P D V_{0}^{A}$ do not get below about $3.5 \%$, which is well above the interest rate in the golden rule (which is equal to $g=2 \%$ ). The reason for this is that the discount rate is the average rate of return on the extra capital which is set aside to compensate future generations, while the interest rate is the marginal rate of return on capital.

\section{Conclusions}

A great advantage of traditional CBAs is that they do not rely on interpersonal welfare comparisons, as they only look for potential Pareto-improvements guided by the Kaldor-Hicks compensation principle. This makes them relatively value-free, at least compared to most alternative decision-guiding procedures. Unfortunately, traditional CBAs assume that the evaluated costs and benefits do not affect the aggregate economy, which is not the case for a nonmarginal event such as climate change. I therefore analyzed in this paper how the Kaldor-Hicks compensation principle can be used to evaluate the economic cost of a non-marginal future event.

The main result of the analysis is that with decreasing returns to capital, this non-marginality forces us to take a stand of who should bear the cost 
of the event; and if the current generations should bear the cost, its present discounted value may be impossible to compute.

This may be particularly relevant for climate change CBAs. Suppose that future generations are entitled to a world without climate change, and that the cost of climate change should therefore be borne by the current generations. A simple calibration with standard parameter values suggests then that the PV of the economic cost of climate change according to the Kaldor-Hicks compensation principle cannot be computed: decreasing returns to capital make it impossible to amass sufficient extra capital to compensate future generations according to their WTA - which defeats the tyranny of discounting.

This has two important policy implications. First, if the PV of the economic cost of climate change cannot be computed according to the KaldorHicks compensation principle, a meaningful climate change CBA is impossible without resorting to a full-fledged social welfare analysis with a well-specified social welfare function - which inevitably involves important value judgements. Second, climate change CBAs often favor an environmental trust fund to compensate future generations for the damage of climate change, rather than financing mitigation projects to avoid climate change - see, for instance, Richard Tol's contribution to Bjorn Lomborg's Copenhagen Consensus (Tol, 2009), and Becker et al. (2011). Unfortunately, these CBAs do not take into account that the rate of return on these trust funds will decrease as capital accumulation pushes the economy towards its golden rule. An environmental trust fund no matter how large it is - may therefore fail to adequately compensate future generations according to their WTA. 


\section{References}

Arrow, K.J., W.R. Cline, K.-G. Maler, M. Munasinghe, R. Squitieri, J.E. Stiglitz (1996), "Intertemporal equity, discounting and economic efficiency", in J.P. Bruce, H. Lee, and E.F. Haites (eds.), Climate Change 1995 - Economic and Social Dimensions of Climate Change, Cambridge University Press, Cambridge, UK.

Becker, Gary S., Kevin M. Murphy, and Robert H. Topel (2011), "On the Economics of Climate Policy", The B.E. Journal of Economic Analysis \& Policy, 10(2), pp. 19.

Bernanke, Ben S. , and Refet S. Gurkaynak (2001), "Is Growth Exogenous? Taking Mankiw, Romer, and Weil Seriously", in Ben S. Bernanke and Kenneth Rogoff (eds,), NBER Macroeconomics Annual, MIT Press, Cambridge, MA.

Caselli, Francesco , and James Feyrer (2007), "The Marginal Product of Capital", Quarterly Journal of Economics, 122(2), 535-568.

Dietz, Simon, and Cameron Hepburn (2010), "On Non-Marginal Cost-Benefit Analysis", Grantham Research Institute on Climate Change and the Environment, Working Paper No. 18, London School of Economics.

Farmer, J. Doyne, and John Geanakoplos (2009), "Hyperbolic discounting is rational: valuing the far future with uncertain discount rates", Cowles Foundation Discussion Paper No. 1719.

Gollier, Christian (2008), "Discounting with Fat-Tailed Economic Growth", Journal of Risk and Uncertainty, 37, 171-186.

Gollier, Christian (2011), "Discounting and risk-adjusting non-marginal investment projects", European Review of Agricultural Economics, 38(3), 325-334.

Gollier, Christian, Phoebe Koundouri, and Theologos Pantelidis (2008), "Declining discount rates", Economic Policy, 23(56), 757-795.

Gollier, Christian, and Martin L. Weitzman (2010), "How should the distant future be discounted when discount rates are uncertain?", Economics Letters, 107(3), 350-353.

Gollier, Christian, and Richard Zeckhauser (2005), "Aggregation of heterogeneous time preferences", Journal of Political Economy, 113(4), 878-896.

Gollin, Douglas (2002), "Getting Income Shares Right", Journal of Political Economy, 110(2), 458-474. 
Goulder, Lawrence H., and Roberton C. Williams, III (2012), "The Choice of Discount Rate for Climate Change Policy Evaluation", Climate Change Economics, $1-18$.

Groom, Ben, Phoebe Koundouri, Ekaterini Panopoulou, and Theologos Pantelidis (2007), "Discounting the distant future: how much does model selection affect the certainty equivalent rate?", Journal of Applied Econometrics, 22, 641-656.

Hepburn, Cameron, Phoebe Koundouri, Ekaterini Panopoulou, and Theologos Pantelidis (2009), "Social discounting under uncertainty: A cross-country comparison", Journal of Environmental Economics and Management, 57, 140-150.

Heston, Alan, Robert Summers, and Bettina Aten (2011), Penn World Tabel Version 7.0, Center for International Comparisons of Production, Income and Prices at the University of Pennsylvania, May 2011.

Hicks, John R. (1939), "Foundations of Welfare Economics", Economic Journal, 49, 696-712.

Hicks, John R. (1943), "The Four Consumer's Surpluses", Review of Economic Studies, 1, 31-41.

Kaldor, Nicholas (1939), "Welfare Propositions of Economics and Interpersonal Comparisons of Utility", Economic Journal, 49, 549-552.

Newell, Richard G., and William A. Pizer (2003), "Discounting the distant future: how much do uncertain rates increase valuations?", Journal of Environmental Economics and Management, 46, 52-71.

Pearce, David, Ben Groom, Cameron Hepburn, and Phoebe Koundouri (2003), "Valuing the Future", World Economics, 4(2), 121-141.

Portney, Paul R., and John P. Weyant (eds.) (1999), Discounting and Intergenerational Equity, Resources for the Future: Washington, D.C.

Stern, Nicholas (2007), The Economics of Climate Change: The Stern Review, Cambridge: Cambridge University Press.

Tol, Richard S.J. (2009), "An Analysis of Mitigation as a Response to Climate Change", Copenhagen Consensus Center.

Weitzman, Martin L. (1998), "Why the Far-Distant Future Should Be Discounted at Its Lowest Possible Rate", Journal of Environmental Economics and Management, 36, 201-208. 
Table 1: $\sigma_{\max }$ across the world

\begin{tabular}{|c|c|c|c|c|c|c|}
\hline \multirow[t]{2}{*}{ Country } & \multirow[b]{2}{*}{ Code } & \multirow[b]{2}{*}{$s$} & \multicolumn{2}{|c|}{$\begin{array}{c}\text { Neglecting } \\
\text { non-reproducible } \\
\text { capital }\end{array}$} & \multicolumn{2}{|c|}{$\begin{array}{c}\text { Taking account of } \\
\text { non-reproducible } \\
\text { capital }\end{array}$} \\
\hline & & & $\alpha$ & $\sigma_{\max }$ & $\alpha$ & $\sigma_{\max }$ \\
\hline Australia & AUS & 21 & 32 & 3.7 & 18 & - \\
\hline Austria & AUT & 22 & 30 & 1.7 & 22 & - \\
\hline Burundi & BDI & 12 & 25 & 7.9 & 3 & - \\
\hline Belgium & BEL & 23 & 26 & 0.2 & 20 & - \\
\hline Bolivia & BOL & 12 & 33 & 21.7 & 8 & - \\
\hline Botswana & BWA & 36 & 55 & 10.9 & 33 & - \\
\hline Canada & CAN & 18 & 32 & 6.8 & 16 & - \\
\hline Switzerland & CHE & 27 & 24 & - & 18 & - \\
\hline Chile & CHL & 20 & 41 & 17.6 & 16 & - \\
\hline Cote d'Ivoire & CIV & 8 & 32 & 38.7 & 6 & - \\
\hline Congo & COG & 19 & 53 & 64.9 & 17 & - \\
\hline Colombia & COL & 21 & 35 & 6.9 & 12 & - \\
\hline Costa Rica & CRI & 18 & 27 & 3.0 & 11 & - \\
\hline Denmark & DNK & 19 & 29 & 3.1 & 20 & 0.0 \\
\hline Algeria & DZA & 35 & 39 & 0.3 & 13 & - \\
\hline Ecuador & $\mathrm{ECU}$ & 28 & 55 & 30.5 & 8 & - \\
\hline Egypt & EGY & 19 & 23 & 0.5 & 10 & - \\
\hline Spain & ESP & 22 & 33 & 3.5 & 24 & 0.1 \\
\hline Finland & FIN & 23 & 29 & 1.0 & 20 & - \\
\hline France & FRA & 19 & 26 & 1.7 & 19 & - \\
\hline United Kingdom & GBR & 15 & 25 & 4.3 & 18 & 0.4 \\
\hline Greece & GRC & 20 & 21 & 0.0 & 15 & - \\
\hline Ireland & IRL & 22 & 27 & 0.7 & 18 & - \\
\hline Israel & ISR & 25 & 30 & 0.7 & 22 & - \\
\hline Italy & ITA & 22 & 29 & 1.5 & 21 & - \\
\hline Jamaica & JAM & 24 & 40 & 7.9 & 26 & 0.0 \\
\hline Jordan & JOR & 51 & 36 & - & 25 & - \\
\hline Japan & JPN & 30 & 32 & 0.1 & 26 & - \\
\hline Republic of Korea & KOR & 39 & 35 & - & 27 & - \\
\hline Sri Lanka & LKA & 27 & 22 & - & 14 & - \\
\hline Morocco & MAR & 30 & 42 & 3.7 & 23 & - \\
\hline Mexico & MEX & 19 & 45 & 29.2 & 25 & - \\
\hline Mauritius & MUS & 32 & 43 & 3.5 & 33 & 0.0 \\
\hline Malaysia & MYS & 36 & 34 & - & 16 & - \\
\hline Netherlands & NLD & 18 & 33 & 8.8 & 24 & 1.4 \\
\hline Norway & NOR & 24 & 39 & 7.4 & 22 & - \\
\hline New Zealand & NZL & 18 & 33 & 8.4 & 12 & - \\
\hline Panama & PAN & 18 & 27 & 3.2 & 15 & - \\
\hline Peru & PER & 22 & 44 & 18.0 & 22 & - \\
\hline Philippines & PHL & 21 & 41 & 14.7 & 21 & - \\
\hline Portugal & PRT & 26 & 28 & 0.2 & 20 & - \\
\hline Paraguay & PRY & 25 & 51 & 28.0 & 19 & - \\
\hline Singapore & SGP & 45 & 47 & 0.1 & 38 & - \\
\hline El Salvador & SLV & 13 & 42 & 47.3 & 28 & 9.6 \\
\hline Sweden & SWE & 18 & 23 & 1.0 & 16 & - \\
\hline Trinidad and Tobago & TTO & 27 & 31 & 0.3 & 8 & - \\
\hline Tunisia & TUN & 42 & 38 & - & 19 & - \\
\hline Uruguay & URY & 17 & 42 & 30.2 & 18 & 0.1 \\
\hline United States & USA & 19 & 26 & 1.7 & 18 & - \\
\hline Venezuela & VEN & 18 & 47 & 41.9 & 13 & - \\
\hline South Africa & $\mathrm{ZAF}$ & 22 & 38 & 9.4 & 21 & - \\
\hline Zambia & ZMB & 9 & 28 & 20.4 & 6 & - \\
\hline
\end{tabular}

$\underline{\text { Note: }}$ all values are expressed as percentages. 
Figure 1: The $P V$ as a function of $\sigma$

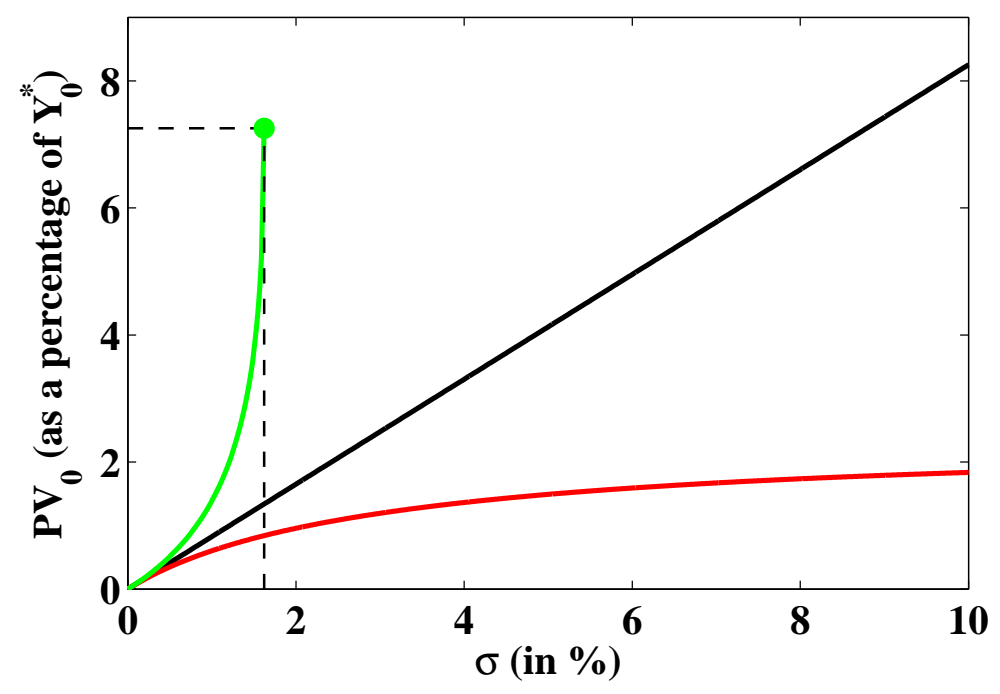

Note: The upper (green) line gives $P V_{0}^{A} / Y_{0}^{*}$; the lower (red) line gives $P V_{0}^{P} / Y_{0}^{*}$; the middle (black) line is $P V_{0} / Y_{0}^{*}$ in the case of standard discounting.

Figure 2: The (implicit) discount rates

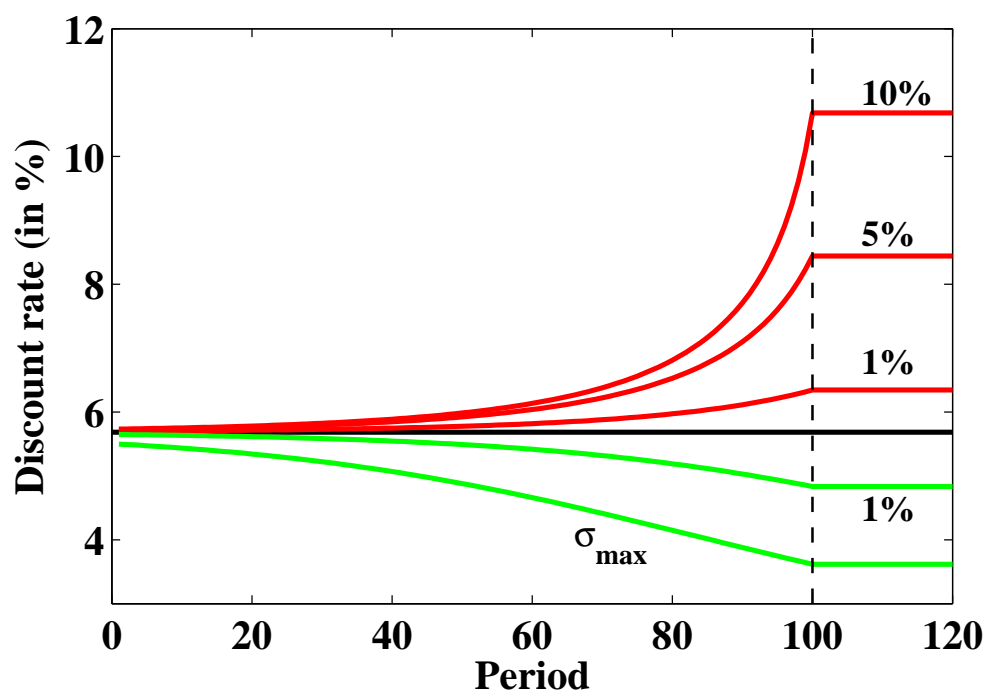

Note: The upward sloping (red) curves give the implicit discount rates for $P V_{0}^{P}$, for different values of $\sigma$ (which are indicated above the curves); the downward sloping (green) curves give the implicit discount rates for $P V_{0}^{A}$, for different values of $\sigma$ (which are indicated below the curves); the horizontal (black) curve is the discount rate with standard discounting. 